\title{
IL-35 Over-expression is Associated with Genesis of Gastric Cancer
}

\author{
Yong-Gang Fan ${ }^{1 \&}$, Jing-Ming Zhai ${ }^{1 \&}$, Wei Wang ${ }^{1}$, Bing Feng ${ }^{1}$, Guo-Liang Yao ${ }^{1}$, \\ Yan-Hui An ${ }^{1}$, Chao Zeng ${ }^{2 *}$
}

\begin{abstract}
Overexpression of interleukin (IL)-35 has been found in a variety of malignancies, but the expression status in gastric cancer has yet to be elucidated clearly. In the present study, positive expression of EBI3 and p35 was 63.3\% and 70.0\% of cases, respectively. EBI3 expression was strongly related with larger tumor size and invasion depth $(\mathrm{P}<0.05)$. Similarly, expression of $\mathrm{p35}$ was also correlated with larger tumor size $(\mathrm{P}<0.05)$. These results indicate that IL-35 might be involved in growth of gastric cancer. Interestingly, EBI3 and p35 expressions were positive correlated with Ki-67 expression. Moreover, EBI3 immunoreactivity was associated with Bcl-2 staining. Our data suggest IL-35 is correlated with genesis of gastric cancer by regulating growth and apoptosis.
\end{abstract}

Keywords: IL-35 - gastric cancer - Ki-67 - Bcl-2

Asian Pac J Cancer Prev, 16 (7), 2845-2849

\section{Introduction}

Interleukin (IL)-35 is a new immune-suppressing cytokine (Schrader., 2002; Niedbala et al., 2007). It is composed of the EBI3 (Epstein-Barr virus-induced gene 3) and IL-12p35 subunits (Devergne et al., 1997; Collison et al., 2007). Taking into account IL-35 is expressed in human regulatory T cells (Tregs) (Pflanz et al., 2006), it is deemed to characteristics of Treg cells. Previous study found IL-35 inhibit advancement of inflammatory diseases by suppressing the activity of effector T cells such as Th2 and Th17 (Collison et al., 2007; Collison et al., 2010; Kochetkova et al., 2010; Seyerl et al., 2010; Huang et al., 2011; Whitehead et al., 2012).

To elucidate the effects of IL-35 in cancer immunity, we studied expression pattern of IL-35 in human gastric cancer. In the procession of study, we observed positive expression of IL-35 in gastric cancer. Recently, Li et al revealed IL-35 could express in a broader tissue apart from Tregs (Li et al., 2012). The immunreactivity of IL-35 was detected in a variety of cancers, such as colon cancer (Zeng et al., 2013), esophageal carcinoma, hepatocellular carcinoma and lung cancer (Long et al., 2013). Moreover, up-regulated expression of EBI3 promoted growth of lung cancer cell, while knockdown of EBI3 prohibited proliferation of lung cancer cell (Long et al., 2013). These data suggested that IL-35 might be participated in tumorigenesis. However, the significance of IL-35 in human gastric cancer was not clarified.

In the present study, we study the expression pattern of IL-35 in gastric cancer samples. In addition, the possible effects for IL-35 expression in the proliferation and apoptosis of human cancer cells were also investigated.

\section{Materials and Methods}

\section{Patients and tissue samples}

Gastric cancer samples were collected from the Department of Pathology, The First Affiliated Hospital of Henan University of Science and Technology between January 2009 and January 2010. Gastric cancer cases included 60 paraffin-embedded samples, with mean age of 54 years (range, 45-65 years). Clinicopathologic features including age, gender, differentiation degree, tumor volume, invasion depth, TNM stage and lymph node metastasis were detailed in Table 1. The informed consent on collection of samples was obtained by each patient. The study was approved by the Medical Ethics Committee of The First Affiliated Hospital of Henan University of Science and Technology.

\section{Tissue microarray and immunohistochemistry}

Paraffin-embedded tissue blocks and the corresponding H\&E-stained slides were overlaid for TMA sampling. Triplicate cylindrical tissues with 0.6-mm diameter were punched from selected tumor areas of individual donor tissue and re-embedded into a recipient paraffin block at the designated place. $4-\mu \mathrm{m}$ sections were cut from the TMAs deparaffinized by routine techniques. The slides were microwaved in citrate buffer for 5 min for antigen retrieval. EBI3 (1:200 dilution, sc-32868, Santa Cruz Biotechnology) and p35 (1:150 dilution, sc-7925,

${ }^{I}$ Departments of General Surgery, the First Affiliated Hospital of Henan University of Science and Technology, Luoyang, ${ }^{2}$ Department of Pathology, Guangdong Medical College, Dongguan, China ${ }^{\star}$ Equal contributors *For correspondence: zengchaosysu@aliyun.com 
Santa Cruz Biotechnology) were applied as primary antibodies. Ki-67(GT209401), Bcl-2 (GM088701) and Bax (A353302) were purchased from Gene Biotechnology (Shanghai, China). Labeling was detected by adding biotinylated secondary antibodies (Maxim-Bio, Fuzhou, China), avidin-biotin complex (Maxim-Bio), and stained with DAB (Maxim- Bio). Finally, the slides were counterstained with Hematoxylin.

\section{Evaluation of EBI3, p35, Bcl-2, Bax and proliferation index $(P I)$}

$\mathrm{EBI} 3, \mathrm{p} 35, \mathrm{Bcl}-2$ and Bax were scored according to the intensity ( 0 , no staining; 1 , weak staining; 2 , moderate staining; 3 , strong staining) and the percentage(extent staining) of cancer cells that were stained ( 0 , no positive cells; $1,>10 \%$ of cancer cells stained; $2,10 \%-50 \%$ of cancer cells stained; $3>50 \%$ of cancer cells stained; $4,>75 \%$ of cancer cells staining positive). If the product of multiplication between staining intensity and the percentage of positive cells is 2 , it is thought as immunoreaction positive (+). Ki-67 was evaluated according the positive number of 100 gastric cancer cells at high magnification.

\section{Statistical analysis}

Statistical analysis was performed by using Student $\mathrm{t}$ test and Spearman correlation analysis in SPSS13.0. The associations of EBI3 and p35 with clinicopathologic factors of gastric cancer cases were evaluated by Fisher's exact test. $\mathrm{P}$ value of less than 0.05 was considered significant.

\section{Results}

EBI3 and p35 expression in gastric cancer and normal tissues

To investigate the expression pattern of IL-35 in gastric cancer tissues, immunohistochemical analysis was utilized to detect EBI3 and p35 in 60 TMA samples. As shown in Figure 1, elevated expression levels of EBI3 and p35 were observed in these samples. In all 60 gastric cancer cases, EBI3 immunoreactivity was present in 38 cases $(63.3 \%, 38 / 60)$. Similarly, p35 staining was observed in
42 among 60 samples $(70.0 \%, 42 / 60)$. Moreover, both IL-35 subunits were expressed in the cytoplasm of the cancer cells. However, it was not detectable the expression of EBI3 and p35 in normal gastric tissues (Figure 1). Significantly, 34(56.7\%, 34/60) cases were positive for both EBI3 and p35.

Correlation of EBI3 and p35 expression with clinicopathological factors of gastric cancer patients

To investigate the clinical significance of IL-35 in gastric cancer, the associations of EBI3 and p35 with clinicopathologic factors were evaluated. As shown in Table 1, larger tumor size $(p=0.025)$, invasion depth $(p=0.017)$ were significantly associated with EBI3 positive expression. Moreover, there was no association between EBI3 expression and the other clinicopathologic parameters, such as gender, age, differentiation degree, lymph node metastasis and TNM stage $(\mathrm{P}>0.05)$. Interestingly, the expression level of p35 was only correlated with larger tumor size $(p=0.034)$. However, no correlation was detected in terms of gender, age, differentiation degree, invasion depth, lymph node metastasis and TNM stage with p35 expression ( $\mathrm{P}>0.05)$.

\section{Associations of EBI3 and p35 expression with PI}

To study the effect of IL-35 on proliferation of gastric cancer, we elucidate the correlation of IL-35 with PI. PI was reflected by $\mathrm{Ki}-67$ in this study. As shown in Figure 2, PI in the group of EBI3 positive expression was significantly higher $(48.5 \pm 6.9)$ compared with that in the negative EBI3 expression group (20.9 \pm 6.3 ) (Table 2). Similarly, PI in the p35 positive expression group was obviously higher than that in he negative $\mathrm{p} 35$ expression group (39.7 \pm 5.6 versus $18.6 \pm 4.8$, Table 3 ). These data suggest IL-35 might be participated in proliferation of gastric cancer.

Association of EBI3 and p35 expression with Bcl-2 and Bax

In all gastric cancer samples, 29 among 38 EBI3stained cases showed Bcl-2 immunoreactivity (Fig.2). Furthermore, in 22 no EBI3-stained cases, 16 cases had not Bcl-2 immunoreactivity (Table 2). A significant

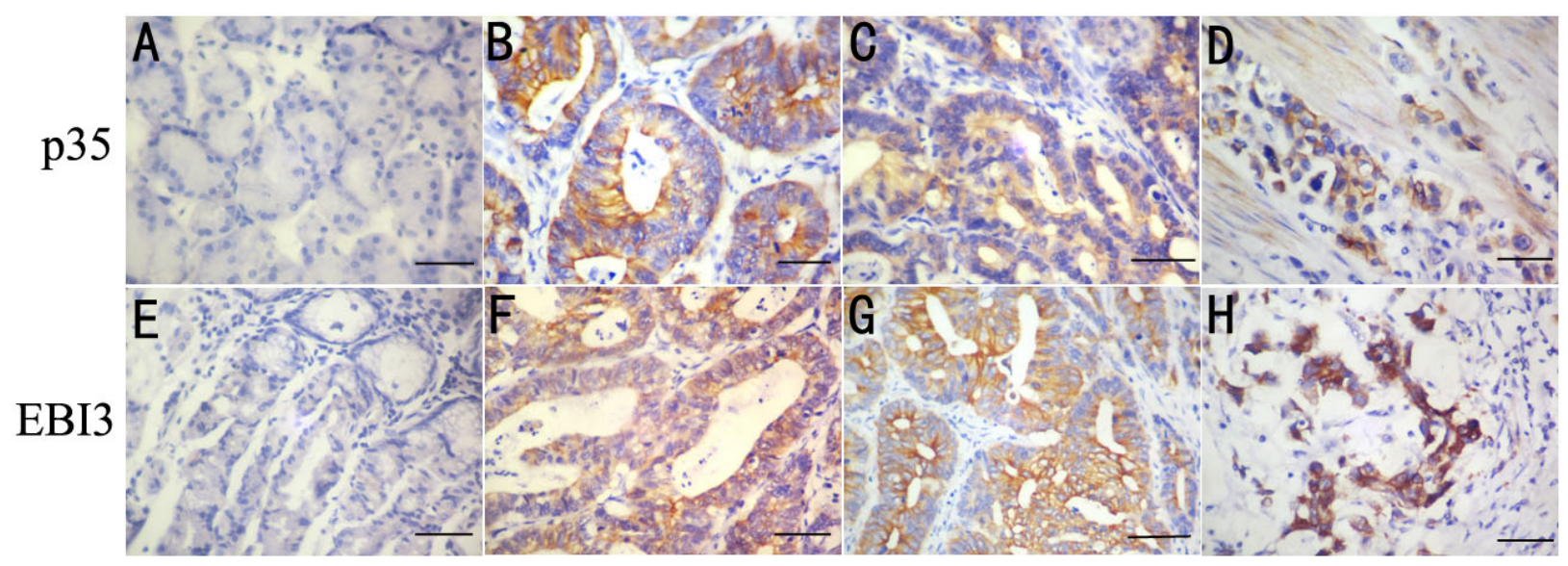

Figure 1. EBI3 and p35 Expression in Gastric Cancer Samples. A, E, No immunoreactivity of EBI3 and p35 in normal gastric tissues. B, C, D, p35 positive expression in well, moderately and poorly differentiated gastric cancer cases. F, G, H, EBI3 staining in well, moderately and poorly differentiated gastric cancer samples. The scale bar is $100 \mu \mathrm{m}$ 
DOI:http://dx.doi.org/10.7314/APJCP.2015.16.7.2845

IL-35 Over-expression is Associated with Genesis of Gastric Cancer

Table 1. Association of EBI3 and p35 Expression with Clinicopathological Factors of Gastric Cancer Patients

\begin{tabular}{|c|c|c|c|c|c|c|c|c|}
\hline \multirow[t]{2}{*}{ Variable } & & \multirow[t]{2}{*}{ No.of cases } & \multicolumn{2}{|c|}{ EBI3 expression } & \multirow[t]{2}{*}{$\mathrm{P}$} & \multicolumn{2}{|c|}{ p35 expression } & \multirow[t]{2}{*}{$\mathrm{P}$} \\
\hline & & & Negative & Positive & & Negative & Positive & \\
\hline \multirow[t]{2}{*}{ Gender } & Male & 32 & 10 & 22 & & 8 & 24 & \\
\hline & Female & 28 & 12 & 16 & 0.425 & 10 & 18 & 0.409 \\
\hline \multirow[t]{2}{*}{ Age (y) } & $\geq 60$ & 34 & 9 & 25 & & 7 & 27 & \\
\hline & M60 & 26 & 13 & 13 & 0.104 & 11 & 15 & 0.091 \\
\hline \multirow[t]{2}{*}{ Tumor size } & $\geq 5 \mathrm{~cm}$ & 19 & 3 & 16 & & 2 & 17 & \\
\hline & M5 cm & 41 & 19 & 22 & 0.025 & 16 & 25 & 0.034 \\
\hline \multirow[t]{2}{*}{ Differentiation degree } & Well/Moderately & 21 & 7 & 14 & & 9 & 12 & \\
\hline & Poorly & 39 & 15 & 24 & 0.783 & 9 & 30 & 0.144 \\
\hline \multirow[t]{2}{*}{ Depth of invasion } & $\mathrm{T} 1+\mathrm{T} 2$ & 43 & 20 & 23 & & 14 & 29 & \\
\hline & $\mathrm{T} 3+\mathrm{T} 4$ & 17 & 2 & 15 & 0.017 & 4 & 13 & 0.55 \\
\hline \multirow[t]{2}{*}{ Lymph node metastasis } & Yes & 23 & 5 & 18 & & 6 & 17 & \\
\hline & No & 37 & 17 & 20 & 0.097 & 12 & 25 & 0.773 \\
\hline \multirow[t]{2}{*}{ TNM stage } & $\mathrm{I}+\mathrm{II}$ & 40 & 13 & 27 & & 13 & 27 & \\
\hline & III+IV & 20 & 9 & 11 & 0.401 & 5 & 15 & 0.766 \\
\hline
\end{tabular}
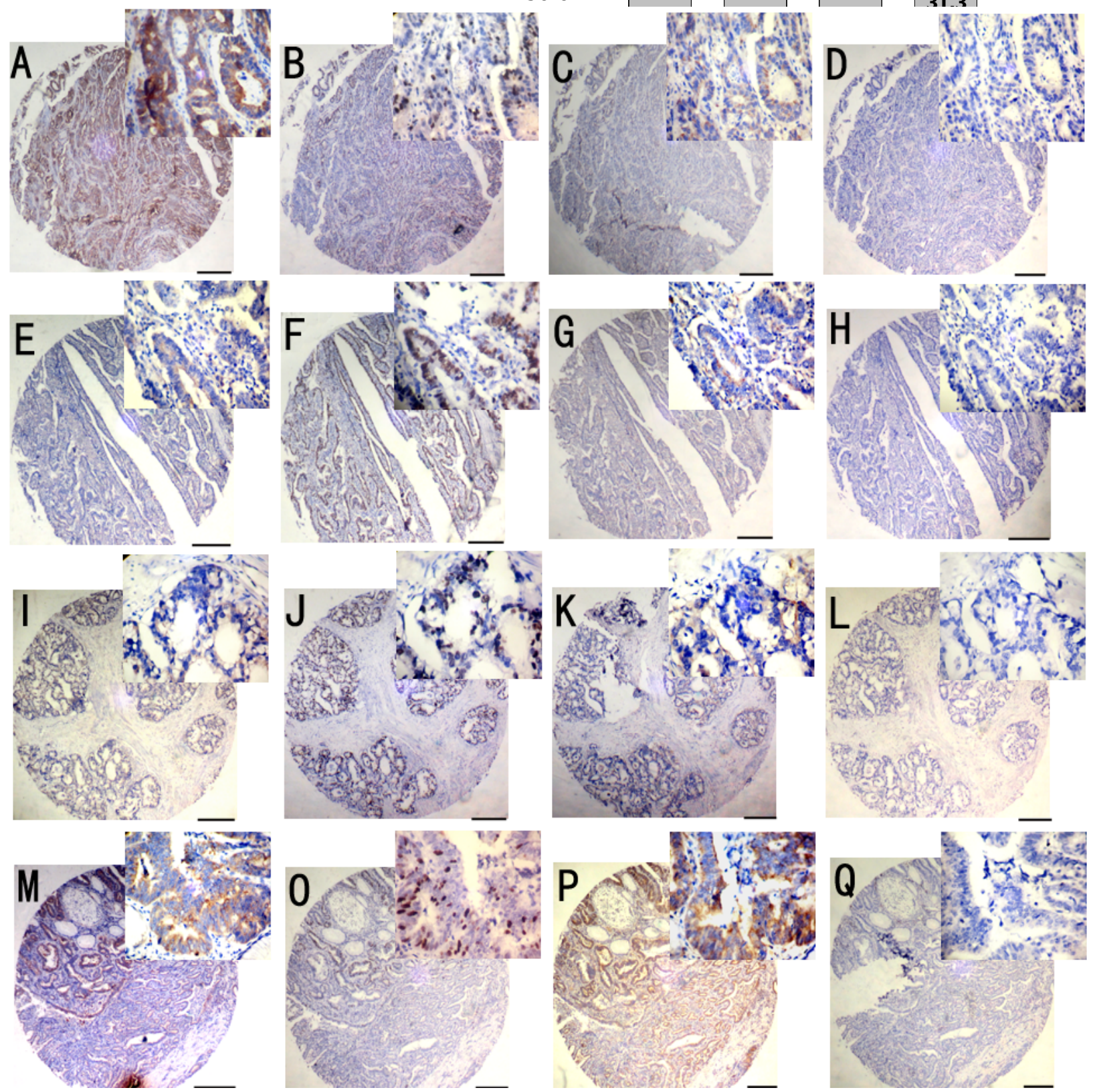

Figure 2. Immunohistochemical Staining of EBI3, p35, Ki-67, Bcl-2 and Bax in Gastric Cancers. A, E, p35 positive expression in gastric cancer cases. I, M, EBI3 staining in gastric cancer samples. B, F, J, O, Expression of Ki-67 in gastric cancers. $\mathrm{C}, \mathrm{G}, \mathrm{K}, \mathrm{P}, \mathrm{Bcl}-2$ staining in gastric cancer cases. D, H, L, Q, No immunoreactivity of Bax in gastric cancer tissues. The scale bar is $500 \mu \mathrm{m}$ 
Table 2. Association of EBI3 with Bcl-2 and PI

\begin{tabular}{|c|c|c|c|c|}
\hline \multirow[t]{2}{*}{ EBI3 } & \multirow[t]{2}{*}{$\mathrm{n}$} & \multicolumn{2}{|c|}{ Bcl-2* } & \multirow[t]{2}{*}{ PI ** } \\
\hline & & + & - & \\
\hline+ & 38 & 29 & 9 & $48.5 \pm 6.9$ \\
\hline- & 22 & 6 & 16 & $20.9 \pm 6.3$ \\
\hline
\end{tabular}

Table 3. Association of $\mathbf{p 3 5}$ with Bcl-2 and PI

\begin{tabular}{|c|c|c|c|c|}
\hline \multirow[t]{2}{*}{ p35 } & \multirow[t]{2}{*}{$\mathrm{n}$} & \multicolumn{2}{|c|}{ Bcl-2* } & \multirow[t]{2}{*}{$\mathrm{PI}^{* *}$} \\
\hline & & + & - & \\
\hline+ & 42 & 20 & 22 & $39.7 \pm 5.6$ \\
\hline- & 18 & 15 & 3 & $18.6 \pm 4.8$ \\
\hline
\end{tabular}

association was found between EBI3 and $\mathrm{Bcl}-2(\mathrm{P}<0.05)$. However, only 20 in 42 p35-stained cases had Bcl-2 immunoreactivity. Among 18 cases with p35 negative expression, 3 cases had not Bcl-2 staining (Table 3). There was no significant correlation between p35 with Bcl-2. Interestingly, we could not detect immunoreactivity of Bax in all gastric cancer samples (Figure 2).

\section{Discussion}

It is generally known that IL-35 as an anti-inflammatory cytokine produced by Treg cells. Recently, several studies found subunits of IL-35 were up-regulated in cancer tissues but not in their nomal counterpart (Niedobitek et al., 2002; Poleganov et al., 2008; Nishino et al., 2011). Moreover, tumor-derived IL-35 promotes tumor growth by enhancing myeloid cell accumulation and angiogenesis (Wang et al., 2013). These results suggested IL-35 might be involved in tumorigenesis and tumor development. However, Long et al reported a new role of IL-35 in inhibiting cancer cell growth, and increasing the apoptosis sensitivity of HepG2 cells through the regulation of genes related to the cell cycle and apoptosis (Long et al., 2013). Therefore, the influence of IL-35 on tumor development, especially on tumorigenesis of gastric cancer is needed to be fully clarified.

In this study, we analyzed IL-35 expression in gastric cancer samples by immunohistochemical assay. Our results have demonstrated that the EBI3 immunreactivity was detected in $63 \%(38 / 60)$ of gastric cancer specimens. Our data were similar with previous observations in lung cancer. Nishino had revealed that expression levels of EBI3 were found to be significantly higher in lung cancer compared with normal lung tissues. Further analyses suggested EBI3 expression was correlated with tumor size and invasion depth (Nishino et al., 2011). Larousserie et al also reported EBI3 is expressed at high levels in EBV-transformed B-cell lines and is induced in vitro by the EBV oncogene LMP1 (Larousserie et al., 2005). The other noteworthy finding is that p35 staining was observed in $70 \%(42 / 60)$ gastric cancer samples. Moreover, p35 expression was correlated with differentiation degree of gastric cancer. Therefore, our data support that IL-35 is correlated with tumorigenesis and progression of gastric cancer.

Previous study reported induction of exogenous EBI3 conferred growth-promoting activity of lung cancer cells. Therefore, we studied the association between expression levels of EBI3 with Ki-67. The results demonstrated EBI3 expression was correlated with PI, suggesting EBI3 might be involved in proliferation of gastric cancer. Interestingly, similar conclusion was obtained from p35 and PI. For thoroughly study the effects of IL-35 on gastric cancer, the correlation of IL-35 with Bcl-2 and Bax. To the best of our knowledge, this is the first study to report the association between IL-35 and apoptosis of cancer cells. Our study observed positive correlation of Bcl-2 staining with EBI3. Therefore, IL-35 might be correlated with tumorigenesis of gastric cancer by controlling the proliferation and apoptosis of gastric cancer cells.

In summary, this study demonstrates IL-35 was highly expressed in gastric cancer and could be as a potential biomarker for diagnosis of gastric cancer. More importantly, IL-35 is correlated with tumorigenesis of gastric cancer. This molecule is a new candidate for the development of new anticancer drugs.

\section{References}

Collison LW, Workman CJ, Kuo TT, et al (2007). The inhibitory cytokine IL- 35 contributes to regulatory T- cell function. Nature, 450, 566-9.

Collison LW, Chaturvedi V, Henderson AL, et al (2010). IL-35mediated induction of a potent regulatory $\mathrm{T}$ cell population. Nat Immunol, 11, 1093-101.

Devergne O, Birkenbach M, Kieff E (1997). Epstein-Barr virusinduced gene 3 and the p35 subunit of interleukin 12 form a novel heterodimeric hematopoietin. Proc Natl Acad Sci USA, 94, 12041-6.

Huang CH, Loo EX, Kuo IC, et al (2011). Airway inflammation and $\operatorname{IgE}$ production induced by dust mite allergen-specific memory/effector Th2 cell line can be effectively attenuated by IL-35. J Immunol, 187, 462-71.

Kochetkova I, Golden S, Holderness K, et al (2010). IL-35 stimulation of CD39+ regulatory $\mathrm{T}$ cells confers protection against collagen II-induced arthritis via the production of IL-10. Immunol, 184, 7144-53.

Larousserie F, Bardel E, Pflanz S, et al (2005). Analysis of interleukin-27 (EBI3/p28) expression in Epstein-Barr virus- and human T-cell leukemia virus type 1-associated lymphomas: heterogeneous expression of EBI3 subunit by tumoral cells. Am J Pathol, 166, 1217-28.

Li X, Mai J, Virtue A, et al (2012). IL-35 is a novel responsive anti-inflammatory cytokine--a new system of categorizing anti-inflammatory cytokines. PLoS One, 7, 33628.

Long J, Zhang X, Wen M, et al (2013). IL-35 over-expression increases apoptosis sensitivity and suppresses cell growth in human cancer cells. Biochem Biophys Res Commun, 430, 364-9.

Niedobitek G, Pazolt D, Teichmann M, et al (2002). Frequent expression of the Epstein-Barr virus (EBV)-induced gene, EBI3, an IL-12 p40-related cytokine, in Hodgkin and ReedSternberg cells. J Pathol, 198, 310-6.

Niedbala W, Wei XQ, Cai B, et al (2007). IL-35 is a novel cytokine with therapeutic effects against collagen- induced arthritis through the expansion of regulatory $\mathrm{T}$ cells and suppression of Th17 cells. Eur J Immunol, 37, 3021-9.

Nishino R, Takano A, Oshita H, et al (2011). Identification of Epstein-Barr virus-induced gene 3 as a novel serum and tissue biomarker and a therapeutic target for lung cancer. Clin Cancer Res, 17, 6272-86. 
Pflanz S, Timans JC, Cheung J, et al (2002). IL- 27, a heterodimeric cytokine composed of EBI3 and p28 protein, induces proliferation of naive CD4 (+) T cells. Immunity, 16, 779-90.

Poleganov MA, Bachmann M, Pfeilschifter J, et al (2008). Genome-wide analysis displays marked induction of EBI3/IL-27B in IL-18-activated AML-derived KG1 cells: critical role of two kappaB binding sites in the human EBI3 promotor. Mol Immunol, 45, 2869-80.

Schrader JW (2002). Interleukin is as interleukin does. Trends Immunol, 23, 573-4.

Seyerl M, Kirchberger S, Majdic O, et al (2010). Human rhinoviruses induce IL-35-producing Treg via induction of B7-H1 (CD274) and sialoadhesin (CD169) on DC. Eur J Immunol, 40, 321-9.

Wang Z, Liu JQ, Liu Z, et al (2013). Tumor-derived IL35 promotes tumor growth by enhancing myeloid cell accumulation and angiogenesis. J Immunol, 190, 2415-23.

Whitehead GS, Wilson RH, Nakano K, et al (2012). IL-35 production by inducible costimulator (ICOS)- positive regulatory $\mathrm{T}$ cells reverses established IL-17-dependent allergic airways disease. J Allergy Clin Immunol, 129, 207-15.

Zeng JC1, Zhang Z, Li TY, et al (2013). Assessing the role of IL-35 in colorectal cancer progression and prognosis. Int $J$ Clin Exp Pathol, 6, 1806-16. 